\title{
Analisis Laporan Keuangan Untuk Mengukur Peningkatan Modal Pada Toko Yanto Swadhipa Natar Lampung Selatan
}

Oleh:

\author{
Habiburahman ${ }^{1}$, Erby Widiasena Wibisono ${ }^{2}$ \\ Fakultas Ekonomi dan Bisnis Universitas Bandar Lampung
}

Jl. Zainal Abidin Pagar Alam No.26, Labuhan Ratu, Kedaton, 35142, Bandar Lampung, Indonesia

Email:

habiburahman@ubl.ac.id

Erby.16011178@student.ubl.ac.id

\begin{abstract}
ABSTRAK
Laporan keuangan sangatlah penting untuk mengetahui status keuangan, maupun sebagai informasi hasil sebuah pencapaian laba yang telah di dapat oleh perusahaan yang bersangkutan. Dengan mengadakan analisis terhadap pos-pos neraca dapat diketahui atau akan diperoleh gambaran tentang posisi keuangan, sedangkan analisa terhadap laporan rugi laba akan memberikan gambaran tentang hasil atau perkembangan usaha perusahaan yang bersangkutan. Tujuan yang ingin dicapai penulis dari penelitian yang dilakukan ini adalah untuk mengetahui kinerja keuangan Toko Yanto Swadhipa, pada tahun anggaran 2016-2018 berdasarkan Rasio Profitabilitas, Rasio Aktivitas. Teknik pengumpulan data yang digunakan dalam penelitian ini yaitu dengan datang langsung ke toko tersebut yang berupa dokumen laporan keuangan Toko Yanto Swadhipa tahun 2019. Metode analisis data yang digunakan adalah metode analisis kualitatif dan analisis kuantitatif. Hasil penelitian dapat disimpulkan Rasio Profitabilitas Toko Yanto Swadhipa pada return on equality dan return on investment terjadi fluktuasi signifikan dikarenakan kurangnya pemanfaatan modal Aktifitas Toko Yanto Swadhipa pada perputaran persediaan juga mengalami penurunan ini kurang baik untuk perkembangan perusahaan.
\end{abstract}

Kata kunci: Kinerja Keuangan, Rasio Likuiditas, Rasio Solvabilitas, Rasio Profitabilitas, dan Rasio Aktivitas.

\begin{abstract}
Abstrack
Financial statements are very important to know the financial status, as well as information on the results of a profit achievement that has been obtained by the company concerned. By carrying out an analysis of the balance sheet posts can be known or will be obtained a picture of the financial position, while analysis of the income statement will provide an overview of the results or business development of the company concerned. Finance Yanto Swadhipa, in the 2016-2018 budget year based On the Profitability Ratio, Activities Ratio. Data collection techniques used in this study is to come directly to the shop in the form of a 2019
\end{abstract}


Yanto Swadhipa Store finance statement document. The data analysis method used is the qualitative analysis method and quantitative analysis. The result of the study can be concluded Yanto Swadhipa Store Profitability Ratios on return on equity and return on investment there are significant fluctuations due to the lack of capital utilization that is less than the maximum then it can be categorized as less good. The Yanto Swadhipa Store Activity Ratio in inventory turnover also decreased in 1 year, namely 2017 due to declining sales. And this decline is not good for company development.

Keyword: Financial Performance, Ratio, Comparative Balance.

\section{Pendahuluan}

Tujuan dari perusahaan pada umumnya adalah ingin memperoleh laba yang maksimal, agar tujuan tersebut dapat tercapai maka perusahaan harus memiliki ketersediaan bahan maupun luasnya jangkauan perusahaan untuk memasarkan barang yang perusahaan miliki, agar perusahaan bisa tetap bertahan dan berkembang dalam sarana pengembangan usaha, tentunya setiap perusahaan harus dikelola dengan baik. Pengelolaan tersebut bergantung pada kemampuan perusahaan menjual barang, membayar biaya lain nya, serta pada akhir nya mencapai laba.

Pada mulanya laporan keuangan bagi suatu perusahaan hanyalah diperuntukan sebagai "alat penguji" dari pekerjaan bagian pembukuan, tetapi untuk selanjutnya laporan keuangan memiliki fungsi tidak hanya menjuru sebagai alat penguji saja tetapi juga sebagai dasar untuk menentukan atau menilai posisi keuangan perusahaan tersebut, dimana dari hasil analisa tersebut, pihak-pihak yang berkepentingan dapat secara mudah mengambil keputusan. Jika perusahaan membuat suatu keputusan keuangan.

Berdasarkan masalah diatas tujuan yang ingin dicapai penulis dari penelitian yang dilakukan ini adalah untuk mengetahui kinerja keuangan Toko Yanto Swadhipa, pada tahun anggaran 2016 - 2018 berdasarkan Rasio Profitabilitas, Raso Aktivitas.

\section{Tinjauan Pustaka}

Menurut Munawir (2002:36) analisis laporan keuangan adalah proses penelaahan atau mempelajari hubungan-hubungan dan tendensi atau kecenderungan (trend) untuk menentukan posisi keuangan dan hasil operasi serta perkembangan perusahaan yang bersangkutan. Kemudian pengertian peningkatan modal Menurut Bambang Riyanto (1998:10) Modal adalah hasil produksi yang digunakan untuk memproduksi lebih lanjut. Dalam perkembangannya kemudian modal ditekankan pada nilai, daya beli atau kekuasaan memakai atau menggunakan yang terkandung dalam barang-barang modal".

Penelitian ini akan membahas laporan keuangan Toko Yanto Swadhipa dengan menggunakan rasio likuiditas, rasio solvabilitas, dan rasio aktivitas kemudian dibandingkan kinerja keuangannya melalui tiga alat analisis tersebut.

\section{Metodologi Penelitian}

Jenis penelitian dalam pengambilan data yang berhubungan dengan permasalahan yang terdapat pada skripsi ini. Penelitian ini menggunakan data kualitatif dan kuantitatif yang berasal dari laporan keuangan Toko Yanto Swadhipa, data yang digunakan adalah tahunan Toko Yanto Swadhipa tahun 2016-2018. 
Populasi atau universe adalah jumlah keseluruhan dari satuan-satuan atau individu-individu yang karakteristiknya hendak diteliti. Dan satuan-satuan tersebut dinamakan unit analisis, dan dapat berupa orang-orang, institusi-institusi, benda-benda, dst. (Djawranto, 1994: 420).

Sampel atau contoh adalah sebagian dari populasi yang karakteristiknya hendak diteliti (Djarwanto, 1994:43). Sampel yang baik, yang kesimpulannya dapat dikenakan pada populasi, adalah sampel yang bersifat representatif atau yang dapat menggambarkan karakteristik populasi.

Metode Analisis data yang digunakan adalah analisis kualitatif dan analisis kuantitatif. Pengertian Kualitatif adalah metode penelitian yang menekankan pada aspek suatu pemahaman secara mendalam terhadap suatu masalah daripada melihat permasalahan untuk penelitian generalisasi. Metode penelitian kualitatif lebih suka menggunakan teknik analisis yang mendalam (in-depth analysis). Yaitu mengkaji suatu masalah secara satu persatu, dari kasus

perkasus. Karena dalam metodologi kulitatif yakin bahwa sifat suatu masalah satu berbeda dengan sifat masalah lainnya.

\section{HASIL PENELITIAN DAN PEMBAHASAN}

\section{Hasil Penelitian}

1. Rasio Profitabilitas yang dihitung dengan cara:

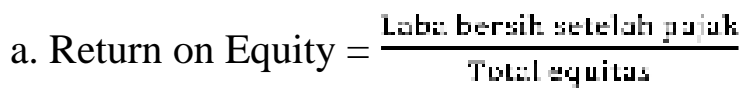

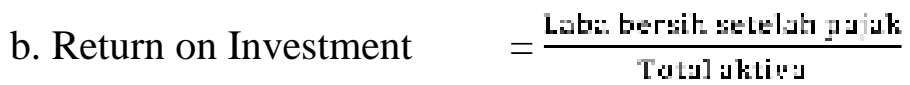

2. Rasio Aktivitas yang dihitung dengan cara:

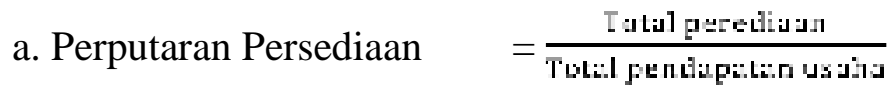

3. Rasio Solvabilitas yang dihitung dengan cara:

a. Debt to Equity Ratio = Tot:I utung

b. Debt to Asset Ratio = $\frac{\text { Toti:l Utang }}{\text { Tatil itsiset }}$

4. Rasio Likuiditas yang dihitung dengan cara:
a. Rasio Lancar
$=\frac{\text { Total axset l:neus }}{\text { Tot:I uting laaeur }}$
b. Rasio Kas

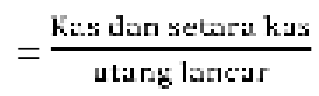

Berdasarkan dari rumus analisis rasio keuangan di atas maka dapat dibandingkan hasil dari tahun sebelumnya dengan hasil tahun yang akan datang.

\section{Rasio Profitabilitas}

Tabel 1 Perbandingan Rasio Profitabilitas Toko Yanto Swadhipa Tahun 2016-2018 


\begin{tabular}{|c|c|c|}
\hline Tahun & ROE & ROI \\
\hline 2016 & $53,31 \%$ & $22,58 \%$ \\
\hline 2017 & $45,22 \%$ & $20,57 \%$ \\
\hline 2018 & $52,14 \%$ & $24,19 \%$ \\
\hline
\end{tabular}

2. Rasio Aktivitas

Tabel 2 Perbandingan Rasio Aktivitas Toko Yanto Swadhipa Tahun 2016-2018

\begin{tabular}{|c|c|}
\hline Tahun & ITO \\
\hline 2016 & $118,37 \%$ \\
\hline 2017 & $119,69 \%$ \\
\hline 2018 & $122,39 \%$ \\
\hline
\end{tabular}

\section{Rasio Solvabilitas}

Tabel 3 Perbandingan Rasio Solvabilitas Toko Yanto Swadhipa Tahun 2016-2018

\begin{tabular}{|c|c|c|}
\hline Tahun & DER & DAR \\
\hline 2016 & $16,45 \%$ & $6,97 \%$ \\
\hline 2017 & $14,98 \%$ & $6,82 \%$ \\
\hline 2018 & $17,14 \%$ & $7,95 \%$ \\
\hline
\end{tabular}

\section{Rasio Likuiditas}

Tabel 4 Perbandingan Rasio Likuiditas Toko Yanto Swadhipa Tahun 2016-2018

\begin{tabular}{|c|c|c|}
\hline Tahun & Current Ratio & Cash Ratio \\
\hline 2016 & $7,32 \%$ & $850,68 \%$ \\
\hline 2017 & $7,21 \%$ & $158,89 \%$ \\
\hline 2018 & $8,38 \%$ & $178,43 \%$ \\
\hline
\end{tabular}

\section{Penutup}

Kesimpulan

Berdasarkan hasil dari penelitian di atas yang dapat disimpulkan pada Toko Yanto Swadhipa periode 2016-2018 apabila ditinjau dari:

1. Rasio Profitabilitas Toko Yanto Swadhipa pada return on equity dan return on investment terjadi fluktuasi signifikan dikarenakan kurangnya pemanfaatan modal yang kurang maksimal maka hal tersebut dapat dikatagorikan kurang baik.

2. Rasio Aktivitas Toko Yanto Swadhipa pada perputaran persediaan juga mengalami penurunan pada 1 tahun yaitu pada tahun 2017 dikarenakan penjualan menurun dan penurunan ini kurang baik untuk perkembangan perusahaan.

3. Rasio Solvabilitas Toko Yanto Swadhipa pada debt to euity ratio dan debt to asset ratio cenderung stabil mengikuti arus pendapatan pada Toko Yanto Swadhipa.

4. Rasio Likuiditas Toko Yanto Swadhipa pada rasio lancar dan kas rasio cenderung stabil mengikuti pendapatan pada Toko Yanto Swadhipa.

\subsection{Saran}


Berdasarkan hasil dari kesimpulan di atas maka dapat disarankan pada Toko Yanto Swadhipa yaitu:

Pada Toko Yanto Swadhipa lebih memanfaatkan modal yang tersedia diimbangi dengan besaran uang yang dipinjam, untuk pemanfaatan peningkatan modal agar mendapatkan laba yang maksimal, dengan cara menambah variasi dan kelengkapan produk disertai pelayanan yang baik.

\section{Daftar Pustaka}

Fahmi,Irfan (2011).Analisis Laporan Keuangan.Lampulo:ALFABETA

Hafsah “Analisis Struktur Modal Terhadap Kinerja Keuangan Pada PerushaanProperti dan Real Estate Yang Terdaftar Di BEI.

Hendry, Andres Maith. (2013) “Analisis Laporan Keuangan Dalam Mengukur Kinerja Keuangan

Pada PT. Hanjaya Mandala Sampoerna Tbk” Fakultas Ekonomi dan Bisnis Universitas Sam Ratulangi Manado. Jurnal Akuntansi Universitas Sam Ratulangi Manado Volume 1 No.3, September 2013, Hal. 619-628

Kurnia Dwi Ramadhan dan La Ode Syarfan “Analisis Laporan Keuangan Dalam Mengukur Kinerja Perusahaan Pada PT. Ricky Kurniawan Kertapersada (Makin Group) Jambi.

Tony Setyo Prayogo ${ }^{1}$ dan Achmad Maqsudi ${ }^{2, ~ “ A n a l i s i s ~ S u m b e r ~ D a n ~ P e n g g u n a a n ~ M o d a l ~ K e r j a ~}$

Untuk Mengukur Kinerja Keuangan Pada PT. Timah (Persero) Tbk (Pengamatan Di BEI Periode Tahun 2009-2012)

Wayan Didik Kuswara (2018) “Analisis Kinerja Keuangan Pada PT. Jasa Marga (Persero) Tbk Periode 2014-2018. 